\section{BMJ Open Respiratory Research}

\title{
Effect of high-flow nasal therapy during acute aerobic exercise in patients with chronic obstructive pulmonary disease after exacerbation: protocol for a randomised, controlled, cross-over trial
}

Guillaume Prieur, ${ }^{1}$ Clement Medrinal, ${ }^{2,3}$ Yann Combret, ${ }^{4,5}$

Aurora Robledo Quesada, ${ }^{6}$ Fabrice Prieur, ${ }^{7,8}$ Jean Quieffin, ${ }^{6}$ Jean Christian Borel, ${ }^{9}$ Gregory Reychler ${ }^{10}$

To cite: Prieur G, Medrinal C, Combret $Y$, et al. Effect of high-flow nasal therapy during acute aerobic exercise in patients with chronic obstructive pulmonary disease after exacerbation: protocol for a randomised, controlled, cross-over trial. BMJ Open Resp Res 2017;4:e00191. doi:10.1136/ bmjresp-2017-000191

Received 14 March 2017 Revised 13 May 2017 Accepted 12 July 2017
CrossMark

For numbered affiliations see end of article.

Correspondence to Dr Guillaume Prieur; gprieur.kine@gmail.com

\section{ABSTRACT}

Introduction Early pulmonary rehabilitation is recommended after a severe exacerbation of chronic obstructive pulmonary disease (COPD). However, this is difficult to implement, particularly for exercise training. High-flow nasal therapy (HFNT) may reduce the work of breathing and dyspnoea and may improve exercise tolerance.

Methods and analysis This is a single-centre, prospective, controlled, randomised, cross-over study. Eligible patients will have a diagnosis of COPD (postbronchodilator forced expiratory volume in $1 \mathrm{~s} /$ forced vital capacity ratio of $<0.7)$. Two constant work rate exercise tests at $80 \%$ of the peak work rate will be carried out on two consecutive days with and without HFNT. The primary outcome will be the difference in endurance time between the two conditions. Secondary outcomes will be the change in muscle oxygenation during exercise, dyspnoea and muscle fatigue, respiratory muscle strength after exercise, respiratory rate, cardiac frequency, transcutaneous $\mathrm{CO}_{2}$ pressure and pulsed $\mathrm{O}_{2}$ saturation. Nineteen patients will be included. Data will be analysed as intention to treat by a blinded statistician.

Ethics and dissemination Ethics approval has been obtained from the Ethics Committees Nord-Ouest III, Caen, France (N ID RCB: 2016-A01325-46). The study will begin in April 2017 for a duration of 2 years. The results of the trial will be presented at national and international meetings and published in peer-reviewed journals. Trial registration number NCT03058081.

\section{INTRODUCTION}

Chronic obstructive pulmonary disease (COPD) is characterised by non-reversible bronchial obstruction associated with systemic disorders and comorbid factors. As the disease progresses, the patient frequently experiences episodes of exacerbation that lead to a progressive worsening of respiratory function and vital prognosis. ${ }^{12}$ Exacerbations are frequently accompanied by several months of increased anxiety, limitations in activities of daily living and reduced quality of life. ${ }^{34}$ Early pulmonary rehabilitation (PR) is recommended following an exacerbation in order to limit these consequences. ${ }^{5}$ However, functional signs of dyspnoea 'too breathless' and fatigability 'too weak' often lead patients to abandon PR programmes prematurely. ${ }^{67}$ Some patients are unable to reach the required training intensity to achieve clinical or physiological benefits. High-flow nasal therapy (HFNT) can deliver up to $60 \mathrm{~L} / \mathrm{min}$ of reheated, humidified air via nasal cannula, with or without additional oxygen. Above a flow of $20 \mathrm{~L} / \mathrm{min}$, HFNT generates a positive pressure in the upper airways. ${ }^{8}$ It induces an increase in alveolar ventilation, improvements in gas exchange and a reduction in ventilatory work in patients with COPD. ${ }^{8-10}$ Currently, one pilot study has demonstrated that HFNT can increase exercise tolerance in patients with severe COPD in a stable state. ${ }^{11}$ To our knowledge, no studies have evaluated the effect of HFNT during exercise after a severe exacerbation. We hypothesised that HFNT could be a simple and effective strategy to improve exercise tolerance following a severe exacerbation.

The primary aim of this randomised, controlled, cross-over study is to evaluate the impact of HFNT on endurance time (TLim) in patients with severe COPD post exacerbation.

The secondary aims are to evaluate the impact of HFNT on tissue oxygenation, dyspnoea and muscle fatigue, transcutaneous $\mathrm{CO}_{2}$ pressure $\left(\mathrm{PtCO}_{2}\right)$, respiratory rate $(\mathrm{RR})$, cardiac rate $(\mathrm{CR})$, pulsed $\mathrm{O}_{2}$ 


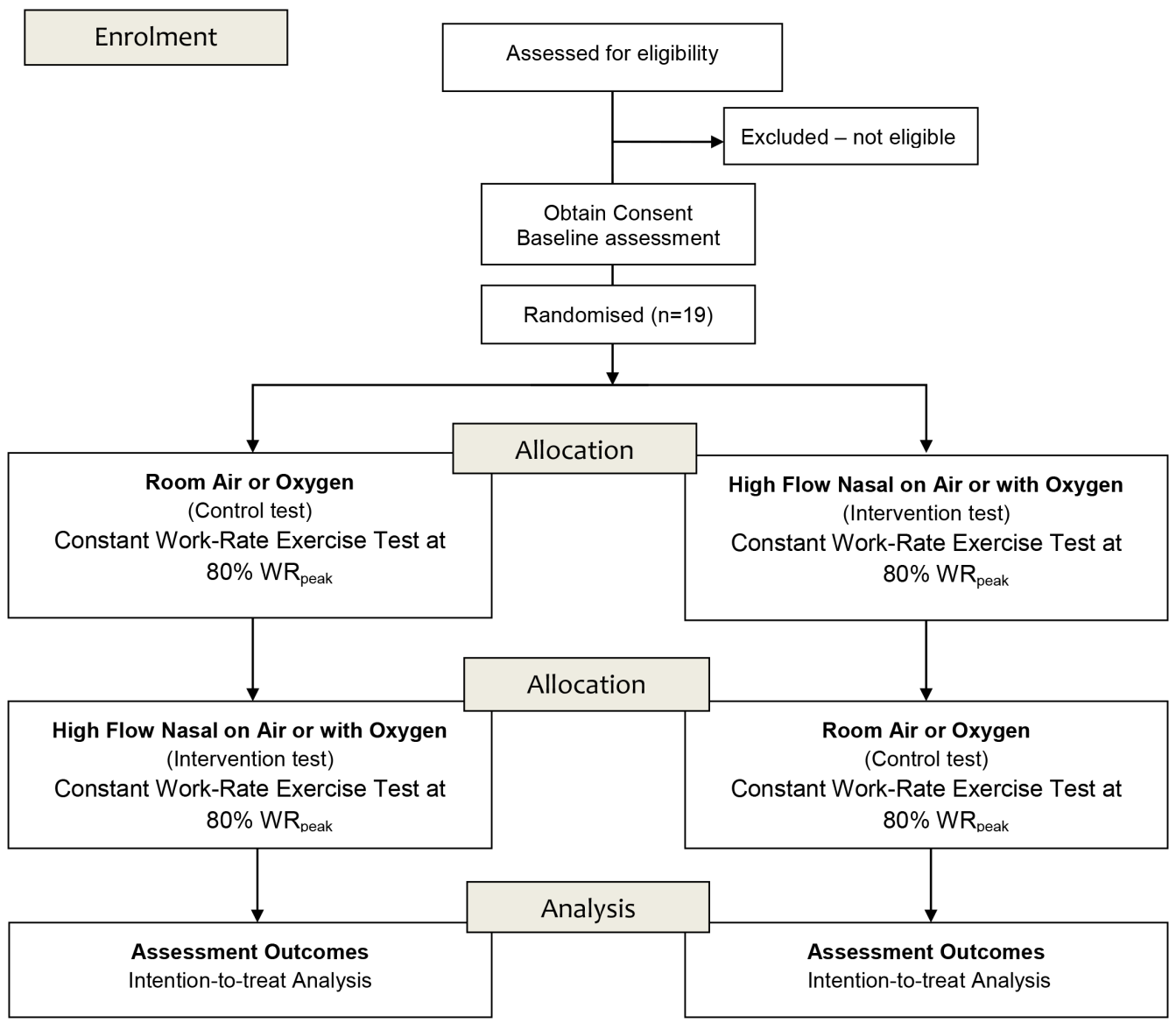

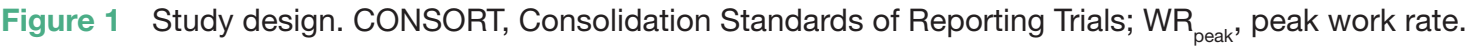

saturation $\left(\mathrm{SpO}_{2}\right)$ during exercise and respiratory muscle fatigue.

\section{METHODS AND ANALYSIS \\ Design}

This is a prospective, single-centre, randomised, controlled, cross-over study. It will compare TLim on constant work rate exercise tests (CWRET) at $80 \%$ of the peak work rate estimated $\left(\mathrm{WR}_{\text {peak }}\right)$ with $60 \mathrm{~L} / \mathrm{min}$ of HFNT (HFNT test) and without HFNT (control test) (figure 1). The results will be analysed as intention to treat. This study will be conducted, analysed and reported according to the Consolidation Standards of Reporting Trials (CONSORT) statement for randomised controlled trials.

\section{Participants}

Patients will be eligible for inclusion if they fulfil the following criteria: (1) a diagnosis of COPD (postbronchodilator forced expiratory volume in $1 \mathrm{~s} /$ forced vital capacity ratio $<0.7$ ), and (2) having given informed consent. The postexacerbation period is defined as less than 7 days postdischarge from the pulmonary department.

Patients will be excluded if they have (1) cardiovascular contraindications to respiratory rehabilitation, (2)
$\mathrm{pH}<7.35$, (3) body temperature $>38^{\circ} \mathrm{C}$, (4) resting tachycardia $>100 \mathrm{bpm}$, (5) systolic arterial pressure $<100 \mathrm{~mm}$ $\mathrm{Hg}$ at rest, (6) musculoskeletal or neurological disorders that could limit exercise performance, (7) if the patient is judged to be at risk by the medical team, (8) if the patient is under guardianship or incarcerated, and (9) if the patient's general state changes between the beginning and end of the study.

Patients will be recruited on admission to the Pulmonary Rehabilitation Department of Jacques Monod Hospital, Le Havre, France. They will be screened for eligibility by a pulmonologist. Participants will receive oral and written information regarding the organisation of the study from the pulmonologist. Written informed consent will be obtained for each participant. The study will begin in April 2017. Each patient will be included for 2 years.

\section{Baseline assessment}

Medical history, comorbid factors, medications and blood gases (carried out on admission to the PR department) will be collected. Respiratory function at rest (spirometry and plethysmography) will be carried out on admission according to the American Thoracic Society/ European Respiratory Society ${ }^{12}$ recommendations. Dyspnoea (modified Medical Research Council and 
Multidimensional Dyspnea Profile), quality of life (St George's Respiratory Questionnaire) and anxiety/ depression (Hospital Anxiety Depression Scale) will be evaluated prior to inclusion.

Two 6 min walk tests (6MWT) will be carried out on admission to the PR department. ${ }^{13}$ The following day, the CWRET will be carried out at $80 \%$ of the $\mathrm{WR}_{\text {peak }}$ estimated by the best 6MWT (according to the equation by Hill et $\left.a l^{14}\right)$. This estimation of maximal power is associated with an average error of $22 \% \pm 18 \% .{ }^{15}$ To compensate for the variability of this estimation, the intensity of the initial CWRET will be adjusted if the TLim is less than $5 \mathrm{~min}$ or more than $15 \mathrm{~min}$, and the intensity of work will be increased or decreased by $20 \%$. Initially, the aim of the test will be to accustom the patient to the instructions. Then, the CWRET will be used to titrate the oxygen flow for patients on long-term oxygen therapy in order to achieve $90 \% \mathrm{SpO}_{2}$ during exercise. The same flow will be administered in all conditions (HFNT or oxygen alone) and will not be modified for the duration of the study. After 1-hour rest, the patient will be given familiarisation time with the HFNT during exercise (cycle ergometer) for $10 \mathrm{~min}$.

\section{Interventions}

After randomisation, two CWRET will be carried out on a cycle ergometer at $80 \%$ of $\mathrm{WR}_{\text {peak }}$ estimated on two consecutive days. The tests will be carried out at the same time of day and the patient will be asked to limit any efforts in between the tests (no exercise sessions). Patients will also be asked not to eat or drink tea or coffee during the 2 hours preceding the tests. If the patient is under $\mathrm{O}_{2}$ supplementation, the titrated oxygen flow determined at the baseline assessment will be the same for each test.

\section{High-flow nasal test}

The AIRVO 2 (Fisher \& Paykel, Auckland, New Zealand) system will be used to provide HFNT. The air will be administered via nasal cannula (Optiflow, Fisher \& Paykel). This system generates humidified, reheated air (between $31^{\circ} \mathrm{C}$ and $37^{\circ} \mathrm{C}$ ) up to $60 \mathrm{~L} / \mathrm{min}$. Fractional inspired oxygen $\left(\mathrm{FiO}_{2}\right)$ can be controlled by altering the $\mathrm{O}_{2}$ supplementation within the system $\left(0.21-1 \mathrm{FiO}_{2}\right)$.

The flow will be set to $60 \mathrm{~L} / \mathrm{min}$ (with or without oxygen supplementation) during the exercise. The air will be warmed to $34^{\circ}$ to ensure effective humidification of the airways as well as the patient's comfort. The patient will be instructed to breathe as he prefers (nasally, orally or both). For patients under oxygen, the $\mathrm{O}_{2}$ flow will be added to the AIRVO 2 device.

\section{Control test}

The test will be carried out on ambient air. For patients who require oxygen supplementation, standard nasal cannula will be used. We have chosen a control test using ambient air or $\mathrm{O}_{2}$ (for patients on long-term oxygen therapy) instead of a placebo (HFNT cannula with no or low flow) since this can increase inspiratory resistance during exercise because of the partial occlusion of the nostrils. This occlusion can increase respiratory work and alter the patient's performance. We chose not to use a Venturi mask for comparison because its effects on patient performance are not known.

\section{Primary outcome}

The primary outcome is TLim during the CWRET. The CWRET will begin with a 3 min warm-up at 15 watts (minimal resistance of the cycle ergometer), followed by a phase of exercise at $80 \%$ of $\mathrm{WR}_{\text {peak }}$ estimated. During the exercise phase, work will be considered maximal if the patient cannot maintain the imposed peddling frequency $(60 \pm 5 \mathrm{revs} / \mathrm{min})$ for $10 \mathrm{~s}$ and/or if the dyspnoea is too severe. In order to avoid involuntarily influencing patients, no encouragements will be provided during the test. After the test, patients will be given a 3 min active recovery phase $\left(<30 \% \mathrm{WR}_{\text {peak }}\right.$ estimated). If the patient reaches $15 \mathrm{~min}$, the test will be stopped by the technicians. The tests will be supervised by two physiotherapists with more than 2 years of experience in carrying out the CWRET with patients with COPD. They will independently record the time using a stopwatch and the mean of the two recordings will be calculated. The two physiotherapists will supervise all the sessions for the whole duration of the study.

\section{Secondary outcome measures}

Three measures of maximal inspiratory and expiratory pressure will be carried out to evaluate the strength of the inspiratory and expiratory muscles, before and after each test. The best value of the three will be used in the analysis. An electronic manometer MicroRPM (Micro Medical, Rhymney, UK) will be used according to international recommendations. ${ }^{16}$ These measures will be taken before and at the end of the exercise $(<5 \mathrm{~min})$ to evaluate the fatigability of the respiratory muscles.

Dyspnoea and muscle fatigue will be evaluated using the modified Borg scale (from 0 to $10 ; 0=$ no fatigue or dyspnoea and $10=$ maximal effort). This will be rated every 2 min during the test and on exhaustion. The maximal clinically important difference is 1 point. ${ }^{17} 18$

$\mathrm{CR}, \mathrm{SpO}_{2}$ and $\mathrm{PtCO}_{2}$ will be carried out using the SenTec (SenTec AG, Therwil, Switzerland). RR will be monitored cycle to cycle by respiratory plethysmography by inductance using the Embletta Gold (Embla, Broomfield, USA). These measures will be taken throughout the duration of the tests. Means will be calculated every minute over a $20 \mathrm{~s}$ interval.

Peripheral muscle oxygenation of the right quadriceps muscle will be evaluated by spectroscopy in the near infrared (NIRS) using a PortaMon (Artinis Medical Systems, Einsteinweg, The Netherlands) device. The NIRS technique is based on the emission and reception of light in the near-infrared region of the spectrum on the surface 
of the tissues. NIRS technology continuously measures the relative changes of muscle oxygenated haemoglobin and myoglobin $(\operatorname{oxy}(\mathrm{Hb}+\mathrm{Mb}))$, deoxygenated haemoglobin and myoglobin $(\operatorname{deoxy}(\mathrm{Hb}+\mathrm{Mb}))$ and total $(\mathrm{Hb}+$ $\mathrm{Mb}$ ) (as the sum of $\operatorname{oxy}(\mathrm{Hb}+\mathrm{Mb})$ and $\operatorname{deoxy}(\mathrm{Hb}+\mathrm{Mb})$ ). This parameter is used to estimate changes in local blood volume. An oxygenation index will be calculated: (tissue saturation index $(\mathrm{TSI})=100 \times(\operatorname{oxy}(\mathrm{Hb}+\mathrm{Mb}) / \operatorname{total}(\mathrm{Hb}$ $+\mathrm{Mb})$ ). The NIRS will be attached to the vastus lateralis muscle, $12 \mathrm{~cm}$ above the lateral femoral condyle using a Velcro band. The device will be covered by a black band in order to eliminate surrounding light. The measures will begin $5 \mathrm{~min}$ before the exercise and will end after 5 min rest after the exercise. This measurement can only be taken on patients with a skinfold measurement less than $3 \mathrm{~cm}$. The distance of separation of between the optodes and the receptor will be $\geq 4 \mathrm{~cm}$ to allow a signal penetration of around $2 \mathrm{~cm}$ depth. The recorded values will be expressed as the delta $(\Delta)$ of the resting baseline values. In order to optimise the intraindividual and interindividual comparability, a maximal voluntary contraction (MVC) will be carried out 2 min after the exercise to determine the maximal or minimal values for the variables evaluated. $\Delta \operatorname{oxy}(\mathrm{Hb}+\mathrm{Mb}), \Delta \operatorname{deoxy}(\mathrm{Hb}+$ $\mathrm{Mb}), \Delta \operatorname{total}(\mathrm{Hb}+\mathrm{Mb})$ and TSI values will be expressed as a $\%$ of the minimal or maximal value determined by the postexercise MVC or on early recovery (whichever is higher).

\section{Sample size}

A sample of 19 patients will be necessary to reject the null hypothesis with a power of $80 \%$ and an alpha risk $\leq 0.05$. We expect a difference of $70 \mathrm{~s}$ on the CWRET (clinically meaningful difference ${ }^{19}$ ) assuming an SD of $104 \mathrm{~s}^{11}$

\section{Randomisation}

$1 / 1$ randomisation will be carried out by the clinical research team using computer software. The randomisation list will be transmitted to the technicians by a person not implicated in the protocol in a sealed envelope. The terms 'HNFT test' and 'Control test' will be replaced by group A or group B by the technicians for each patient to avoid biasing the analysis of the results.

\section{Blinding}

The patients and the technicians will know the order of the tests (HFNT or control) at the first CWRET. The analysis of the data recorded continuously during the tests (RR, CR, $\mathrm{SpO}_{2}, \mathrm{PtCO}_{2}$, muscle oxygenation) will be carried out by technicians who will be blinded to the group. The final statistical analysis will be carried out by a person who will be blinded to group allocation.

\section{Data management and statistical analysis}

Prism 5 (GraphPad, La Jolla, California, USA) software will be used for the statistical analysis. The results will be expressed as means with SD or medians with IQRs depending on their distribution (respectively normal or not normal). Comparison of the TLim (primary outcome) and physiological responses (secondary outcomes) between the two conditions will be carried out using the method described by Wellek and Blettner ${ }^{20}$ in order to evaluate (1) the effect of treatments (HFNT vs control), (2) the effect of treatment sequence (HFNT first vs control first) and (3) the firstorder carryover risk. Physiological variables will be calculated by subtracting the baseline value from the value at the end of each session (HFNT and control). For all tests, significance will be set to $\mathrm{p} \leq 0.05$. Data will be analysed as intention to treat. In the Intention-totreat analysis, if the percentage of missing data is $\leq 5 \%$, data will be replaced by simple imputation (replacement of the missing value by the median of the available values for that variable). If $5 \%-20 \%$ of data are missing, they will be replaced by multiple imputations using a regression model. ${ }^{21}$

\section{ETHICS AND DISSEMINATION}

Ethical approval to conduct the study has been obtained from the Ethics Committees Nord-Ouest III, Caen, France. In conformity with the Declaration of Helsinki, all participants will be recruited to participate voluntarily and they will sign a written informed consent form. The results of the trial will be presented at national and international meetings and published in peer-reviewed journals. Results will be registered at ClinicalTrials.gov. We will also disseminate the main results to all participants in a letter. The study has been registered with ClinicalTrials.gov (NCT03058081).

\section{STRENGTHS AND LIMITATIONS}

The results of this study will bring new elements regarding the feasibility and the effectiveness of HFNT on exercise capacity of patients with COPD after severe exacerbation.

They will also provide additional data such as (1) changes in $\mathrm{PaO}_{2}$ of carbon dioxide during exercise with HFNT, and (2) the effect of HFNT on oxygen consumption in the lower limb muscles.

This study has several limitations: (1) The patient and technicians evaluating the CWRET cannot be blinded to group allocation. However, this test is standardised with well-defined stopping criteria. (2) The study will not provide information regarding the effectiveness of HFNT on long-term exercise capacity. However, it will provide information regarding physiological adaptation to exercise of patients under HFNT. These results could form the basis for a study of long-term effectiveness.

\section{Author affiliations}

${ }^{1}$ Pulmonology Department and Pulmonary Rehabilitation Department, Groupe Hospitalier du Havre, Montivilliers, France

${ }^{2}$ Normandie UnivRouen France Institute for Research and Innovation in Biomedicine (IRIB), Rouen, France

${ }^{3}$ Pulmonology Department Groupe Hospitalier du Havre, Montivilliers, France 
${ }^{4}$ Physiotherapy Department, Groupe Hospitalier du Havre, Montivilliers, France

${ }^{5}$ Institut de Recherche Expérimentale et Clinique (IREC), Pôle de Pneumologie, ORL \& Dermatologie Université Catholique de Louvain, 1200 Brussels, Service de Pneumologie, Cliniques universitaires Saint-Luc, Brussels, Belgium ${ }^{6}$ Pulmonology Department, Groupe Hospitalier du Havre, Montivilliers, France ${ }^{7}$ Université Paris Saclay, Orsay Cedex, France

${ }^{8}$ CIAMS Université d'Orléans, Orléans, France

${ }^{9}$ Research and Development, Association AGIR à dom, Grenoble, France

${ }^{10}$ Institut de Recherche Expérimentale et Clinique (IREC), Pôle de

Pneumologie, ORL \& Dermatologie, Université Catholique de Louvain, 1200 Brussels, Service de Pneumologie, Cliniques universitaires Saint-Luc, Brussels, Belgium

Contributors Trial concept and design: GP, CM, YC, JCB and GR. Acquisition of data: GP, CM, ARQ and YC. Analysis and interpretation of data: GP, GR, FP and JQ. Drafting the article: GP, CM, YC, JCB and GR. Revising it critically for important intellectual content and final approval of the version to be published: all authors. GP had full access to all trial data and takes responsibility for the integrity of the data and the accuracy of the data analysis.

Competing interests None declared.

Patient consent Protocol study.

Ethics approval Ethics Committees Nord-Ouest III, Caen, France.

Provenance and peer review Not commissioned; externally peer reviewed.

Open Access This is an Open Access article distributed in accordance with the Creative Commons Attribution Non Commercial (CC BY-NC 4.0) license, which permits others to distribute, remix, adapt, build upon this work non-commercially, and license their derivative works on different terms, provided the original work is properly cited and the use is non-commercial. See: http://creativecommons.org/ licenses/by-nc/4.0/

(C) Article author(s) (or their employer(s) unless otherwise stated in the text of the article) 2017. All rights reserved. No commercial use is permitted unless otherwise expressly granted.

\section{REFERENCES}

1. Donaldson GC, Seemungal TA, Bhowmik A, et al. Relationship between exacerbation frequency and lung function decline in chronic obstructive pulmonary disease. Thorax 2002;57:847-52.

2. Soler-Cataluña JJ, Martínez-García MA, Román Sánchez P, et al. Severe acute exacerbations and mortality in patients with chronic obstructive pulmonary disease. Thorax 2005;60:925-31.

3. Spencer S, Calverley PM, Burge PS, et al. Impact of preventing exacerbations on deterioration of health status in COPD. Eur Respir J 2004;23:698-702

4. de Miranda S, Pochard F, Chaize M, et al. Postintensive care unit psychological burden in patients with chronic obstructive pulmonary disease and informal caregivers: A multicenter study. Crit Care Med 2011;39:112-8.
5. Celli BR, Decramer M, Wedzicha JA et al. An official American Thoracic Society/European Respiratory Society statement: research questions in COPD. Eur Respir J 2015;45:879-905.

6. Harrison SL, Robertson N, Graham CD, et al. Can we identify patients with different illness schema following an acute exacerbation of COPD: a cluster analysis. Respir Med 2014;108:319-28.

7. Benzo R, Wetzstein M, Neuenfeldt P, et al. Implementation of physical activity programs after COPD hospitalizations: Lessons from a randomized study. Chron Respir Dis 2015;12:5-10.

8. Bräunlich J, Köhler M, Wirtz H. Nasal highflow improves ventilation in patients with COPD. Int J Chron Obstruct Pulmon Dis 2016;11:1077-85.

9. Biselli PJ, Kirkness JP, Grote L, et al. Nasal high-flow therapy reduces work of breathing compared with oxygen during sleep in COPD and smoking controls: a prospective observational study. J Appl Physiol 2017;122:82-8.

10. Fraser JF, Spooner AJ, Dunster KR, et al. Nasal high flow oxygen therapy in patients with COPD reduces respiratory rate and tissue carbon dioxide while increasing tidal and end-expiratory lung volumes: a randomised crossover trial. Thorax 2016;71:759-61.

11. Cirio S, Piran M, Vitacca M, et al. Effects of heated and humidified high flow gases during high-intensity constant-load exercise on severe COPD patients with ventilatory limitation. Respir Med 2016;118:128-32.

12. Brusasco V, Crapo R, Viegi G. Coming together: the ATS/ERS consensus on clinical pulmonary function testing. Eur Respir $J$ 2005;26:1-2.

13. ATS Committee on Proficiency Standards for Clinical Pulmonary Function Laboratories. ATS statement: guidelines for the six-minute walk test. Am J Respir Crit Care Med 2002;166:111-7.

14. Hill K, Jenkins SC, Cecins N, et al. Estimating maximum work rate during incremental cycle ergometry testing from six-minute walk distance in patients with chronic obstructive pulmonary disease. Arch Phys Med Rehabil 2008;89:1782-7.

15. Kirkham AA, Pauhl KE, Elliott RM, et al. Utility of equations to estimate peak oxygen uptake and work rate from a 6-minute walk test in patients with COPD in a clinical setting. $J$ Cardiopulm Rehabil Prev 2015;35:431-8.

16. American Thoracic Society/European Respiratory Society. ATS/ERS statement on respiratory muscle testing. Am J Respir Crit Care Med 2002;166:518-624.

17. Mador MJ, Rodis A, Magalang UJ. Reproducibility of Borg scale measurements of dyspnea during exercise in patients with COPD. Chest 1995;107:1590-7.

18. Ries AL. Minimally clinically important difference for the UCSD Shortness of Breath Questionnaire, Borg Scale, and Visual Analog Scale. COPD 2005;2:105-10.

19. Puente-Maestu L, Palange P, Casaburi R, et al. Use of exercise testing in the evaluation of interventional efficacy: an official ERS statement. Eur Respir J 2016;47:429-60.

20. Wellek S, Blettner M. On the proper use of the crossover design in clinical trials: part 18 of a series on evaluation of scientific publications. Dtsch Arztebl Int 2012;109:276-81.

21. Rubin DB. Multiple imputation for Nonresponse in surveys. John Wiley \& Sons, 2004. 